\title{
A DANÇA DAS FORMAS EM MACUNAÍMA, DE MÁRIO DE ANDRADE E "PERISSÉIA", DE TOM ZÉ
}

\section{THE DANCE OFTHEFORMSAT MACUNAÍMA, BY MÁRIO DE ANDRADE AND “PERISSÉIA” BY TOM ZÉ.}

Alex Alves Fogal ${ }^{1}$

\begin{abstract}
Resumo: O presente trabalho visa comparar a forma composicional da canção, "Perisséia" de Tom Zé à de Macunaíma: o herói sem nenhum caráter, de Mário de Andrade. Conforme espera-se demonstrar, a canção do músico baiano estabelece uma homologia criativa com os princípios formais do livro do escritor modernista.
\end{abstract}

\begin{abstract}
This work aims to compare the compositional form of the song, "Perisséia" by Tom Zé to that of Macunaíma: the hero with out any character, by Mário de Andrade. As we expected to demonstrate, the bahian musician's song establishes a creative homology with the formal principles from the modernist writer's book.
\end{abstract}

Palavras-chave: Música; Literatura; Tom Zé; Mário de Andrade.

Keywords: Music; Literature; Tom Zé; Mário de Andrade.

\section{Introdução}

A relação entre literatura e música pode ser considerada a partir das mais variadas perspectivas e pode levar às mais diversas possibilidades de análise. No presente trabalho interessa tentar compreender como a criação estética, tanto na arte literária quanto na composição musical, se articula a componentes históricos e socias, operacionalizando um tipo de "redução estrutural""na qual a forma artística acaba por absorver dispositivos externos a ela em uma estrutura em que os atributos formais passem a servir de explicação para a sociedade e, em contrapartida, esta esteja representada pelo procedimento da arte.

Talvez possa ser dito que esse ponto de vista se encaixa melhor no caso da literatura, pois muitas das vezes a ligação entre música e sociedade parece menos perceptível, não sendo raro vermos a forma musical ser tratada como algo puro, na qual predominam apenas as propriedades de caráter

\footnotetext{
1 Doutor em estudos literários: literatura brasileira pela Universidade Federal de Minas Gerais (UFMG) e professor do Centro Federal de Educação Tecnológica de Minas Gerais (CEFET-MG).

$2 \mathrm{O}$ conceito é bastante conhecido no campo dos estudos literários e foi cunhado por Antonio Candido em sua obra O discurso e a cidade. Segundo as palavras do crítico, a redução estrutural é um processo "por cujo intermédio a realidade do mundo e do ser se torna, na narrativa ficcional, componente de uma estrutura literária, permitindo que esta seja estudada em si mesma, como algo autônomo".(CANDIDO, 2010, p. 9) Apesar de Candido, no caso, aplicar o conceito a narrativas romanescas, compreendo que este é extremamente produtivo para analisar também outras artes a partir de um ponto de vista dialético que vise elucidar as relações entre estética e sociedade a partir do próprio objeto artístico.
} 
mais técnico, não havendo espaço para reflexões de natureza histórica ou política. Contudo, uma breve explicação de Theodor Adorno no prefácio de sua obra Filosofia da Nova Música, um grande marco nos estudos sobre a estética musical, é capaz de nos indicar o raciocínio contrário:

Este ensaio pretendia expor a mudança da função da música atual, mostrar as transformações internas que os fenômenos musicais sofrem ao serem subordinados, por exemplo, à produção comercializada em massa e também determinar de que maneira certos deslocamentos ou modificações antropológicas da sociedade massificada penetram até na estrutura do ouvido musical. Já então o autor pretendia dar um tratamento dialético à situação da composição musical, a única que na verdade decide sobre a situação da própria música. Saltava-lhe aos olhos a violência da totalidade social, até em domínios como o da música, aparentemente desligados. (ADORNO, 2009, p.9).

No trecho, Adorno refere-se a ele mesmo, sempre em terceira pessoa, para esclarecer suas intenções metodológicas na produção do seu conhecido estudo sobre a música dodecafônica e acaba por iluminar questões imprescindíveis para uma abordagem histórica da forma musical. Afirma-se ali que“a situação da composição musical", ou seja, as condições segundo as quais a obra foi produzida, atuam decisivamente sobre ela, pois, segundo ele, a "totalidade social" atua com "violência" até mesmo em domínios "aparentemente desligados" da conjuntura social, como é o caso da música. É por meio dessa posição analítica que o pensador alemão investigará os matizes sociais das formas composicionais utilizadas por ArnoldSchoenberg eÍgorStravinski.

Entretanto, por mais que seja possível e desejável percorrer esse caminho, poderíamos encontrar uma outra objeção para a intenção de se comparar literatura e música que é a visível diferença que há entre os dois campos artísticos: modos de composição, de fruição, de comercialização, entre outros aspectos. Entretanto, ainda o mesmo Theodor Adorno em sua Teoria Estética nos ensina que a arte, de modo geral e as obras de arte em específico,

são não só heteronomamente dependentes, mas porque na própria constituição da sua autonomia, que ratifica a posição social do espírito cindido segundo as regras da divisão do trabalho, não são apenas arte; surgem também como algo que lhe é estranho e se lhe opõe. Ao seu próprio conceito está mesclado o fermento que a suprime(...) A identidade estética deve defender o não idêntico que a compulsão à identidade oprime na realidade. (ADORNO, 2011, p.16)

Em síntese, devemos lembrar sempre que a obra de arte em sijá carrega o princípio da heteronomia.Sua forma, seja ela literária ou musical, é composta também por elementos externos 
(sociais, ideológicos, históricos), ou seja, seu princípio de construção é fundamentado por uma exogamia. Logo, o eu-lírico de um poema, o narrador de um romance ou o solo de um instrumento em uma composição musical possuem autonomia enquanto dispositivos estéticos da estrutura da obra mas alcançam sentido ainda mais pleno quando cotejados com a realidade externa à realização artística, que por sua vez, deixa de ser meramente externa pois passa a fazer parte da fatura formal. Assim sendo, ao compararmos dois campos artísticos diferentes estamos apenas estimulando o potencial dialético inerente à forma artística autêntica: a identidade que busca o não-idêntico.

Essa curta explicação de caráter mais teórico será a base de todo o percurso analítico que será percorrido ao longo do estudo, cujo objetivo é empreender uma comparação entre a obra Macunaíma, de Mário de Andrade e uma canção de Tom Zé intitulada "Perisséia". A meta será compará-las a partir de alguns elementos que acredito estar presente no método de formulação estética das duas.

\section{A Forma Literária na Forma da Canção}

Tom Zé é um compositor da música brasileira que dispensa grandes apresentações. Sua trajetória sempre foi marcada por uma postura independente, irreverente e pela complexidade de suas produções artísticas. É pertinente dizer que em sua consciência criadora há traços que remetem diretamente ao espírito do movimento modernista, onde Mário de Andrade se insere. Em ambos há o apreço pela experimentação estética, a desconsideração pelas soluções fáceis e, principalmente, a tentativa de estabelecer uma reflexão sobre a formação cultural do povo brasileiro.

Esses aspectos gerais já permitiriam uma interessante aproximação entre Tom Zé e Mário de Andrade. Entretanto, conforme foi mencionado acima, a canção "Perisséia", contida no álbum intitulado Jogos de Armar (2000), de autoria do compositor baiano, se apresenta como um meio muito específico e produtivo para podermos cotejar o projeto poético dos dois artistas, visto que a homologia entre o princípio de composição da canção e o de Macunaíma - conforme espero demonstrar - nos coloca diante de um interessante caso onde a forma de uma narrativa acabou servindo de dispositivo estético para a elaboração de uma obra pertencente a um outro campo artístico. Para que o raciocínio possa ganhar contornos mais nítidos, observemos a letra da canção de Tom Zé:

Sabe com quem tá falando?

Eu sou amigo do rei...

Que importa o nome que eu tenho

Que importa aquilo que eu sou

Se eu tenho um sonho impossível

Pra mim o tempo parou

Meu nom, meu nome é Peri

Revista Crioula - $\mathbf{n}^{\circ} 26$ - Relações entre literatura e música na produção de língua portuguesa

$2^{\circ}$ Semestre 2020 
Meu nom, meu nome é Zumbi

Meu nom, meu nome é Galdino

Meu nome é brasil

Um gigante-menino

Um navio sem destino

No ano dois mil

Coro

Se eu pudesse atrasaria

Este relógio dois mil

Pra rezar na primeira missa

Pelo futuro do brasil

Acalanto

Inheminheminhem

Inheminheminhem

Nhem ... nhemnhem

Nhemnhem

Coro

Iêperiiêperiiê camará

Iêperi camará

Peri brasil

Peri

E eu, o que sou?

E eu, o que sei?

Macunaíma, sou eu?

Tiradentes, sou eu?

Sou eu um poeta

Sou eu um pião?

Quantos anos eu tenho

Quantos anos terei?

Eu que vivo sem, jamais saberei

Ó meu pai, não me abandone,

Minha mãe, como é meu nome

Este mundo tem lei?

Este mundo tem rei?

Revista Crioula - n⿳0 26 - Relações entre literatura e música na produção de língua portuguesa 
Coro

Se eu pudesse atrasaria ... (TOM ZÉ/ CAPINAM, 2000)

Inicialmente é interessante ressaltar que o título da canção remete a Peri, outro personagem indígena da literatura nacional, e não a Macunaíma. Entretanto, apesar do lugar de destaque dado ao nome do herói de O Guarani, a referência não deixa de ser meramente temática, pois o eu-poético da canção de Tom Zé não apresenta pontos em comum com o indígena afidalgado do romance de José de Alencar e nem a estrutura da composição nos faz pensar no modelo literário da narrativa do escritor romântico. A impressão que fica é que o nome de Peri aparece no título somente pelo fato de se tratar de um indígena - traço indispensável ao desenvolvimento da canção - e pela adequação sonora com o fragmento "sséia", que remete diretamente à Odisseia de Homero, na tentativa de se referir à feição épica - ou como veremos mais à frente, à subversão desse aspecto - que caracteriza a empreitada do eu-poético. Em contrapartida, a presença da obra de Mário de Andrade não se esgota na pergunta feita após o segundo coro da canção ("Macunaíma, sou eu?") e sim se mostra como um importante fator de construção que será analisado nas partes seguintes.

\title{
Montagem, Sobreposição e Multiplicidade
}

Assim como em Macunaíma, nota-se que a composição de Tom Zé se afasta de uma condução linear e de uma estrutura unitária fechada, visto que lança mão de elementos da montagem e da justaposição. Junto a isso, é possível afirmar também que possui uma grande intensidade de momentos de variação, principalmente em termos de sonoridade. Quanto ao primeiro aspecto indicado, o da montagem, fica muito claro que a canção se utiliza simultaneamente de elementos retirados de situações e contextos variados, os quais o artista coloca para funcionarem juntos em uma mesma lógica de sentido. Para CristopherDunn, estudioso da estética do artista, a "justaposição contrastante" é uma ferramenta estética indispensável ao método do músico. (DUNN, 2018, p. 1). Um exemplo disso é a própria figura do eu- poético, capaz de se transmutar diversas vezes ao longo da canção:

\author{
Meu nom, meu nome é Peri \\ Meu nom, meu nome é Zumbi \\ Meu nom, meu nome é Galdino \\ Meu nome é Brasil. (TOM ZÉ/ CAPINAM, 2000)
}

Nesse trecho, presente na primeira estrofe da canção, a identidade cambiante do eu-póetico 
primeiramente se assume como "Peri", o herói romântico e europeizado do romance indianista de José de Alencar, em seguida se identifica como "Zumbi" em uma referência direta a Zumbi dos Palmares e, por fim, como "Galdino", uma menção a Galdino Jesus dos Santos, um indígena brasileiro que acabou morto nas ruas de Brasília, no ano de 1997, após ser incendiado por jovens de classe média alta. Nota-se que há uma deliberada repetição ("meu nom, meu nome é") nos versos, como se a voz poética da canção gaguejasse de modo inseguro, mas quisesse demarcar insistentemente a multiplicidade de sua persona, que possui um efeito de sentido específico. No caso, parece correto dizer que a intenção era estabelecer associação com figuras de tempos históricos e contextos bem diferentes, mas que possuem em comum o fato de ocuparem uma posição marginalizada em nosso panorama social e cultural. Peri por exemplo, tanto no plano do romance de Alencar como no âmbito dos estudos literários, é o índio desajustado, uma vez que foi despido de suas características primitivas para integrar-se a um modo de ser mais próximo dos heróis dos romances de cavalaria europeus. A figura de Zumbi remete ao negro escravizado, que nega a condição que lhe foi imposta e se revolta. Já Galdino é o índio do período contemporâneo, tornado indigente e largadoà mercê da barbárie da sociedade. Após esse exercício camaleônico, todos esses seres são sintetizados no verso que diz "Meu nome é Brasill", dando a entender que é ali, entre eles, que reside a aura autêntica da brasilidade. Mais à frente, na última estrofe da canção, o mesmo processo é empregado quando o eu-poético questiona:

E eu, o que sou?
E eu, o que sei?
Macunaíma, sou eu?
Tiradentes, sou eu?

(TOM ZÉ/CAPINAM, 2000).

Aqui, somam-se às figuras já mencionadas, as de Macunaíma e Tiradentes. O primeiro, como se sabe, é uma representação arquetípica da própria ideia de desajuste e marginalidade: desconstrução do ideal romântico sobre os índios; meio primitivo e meio civilizado; herói e anti-herói. O segundo, uma figura histórica carregada de controvérsias e que acabou como mártir de uma conjuração fracassada. Vê-se que há ali o remendo de etapas históricas, fatos e imagens diversas por meio de um mesmo fio condutor, em um processo de sobreposição de camadas cuja função é demonstrar como essa odisseia tratada pela canção é a saga dos flageladose dos sem lugar no "navio sem destino" que serve de alegoria para o país.

Esse procedimento de montagem possui uma grande importância também na estratégia que Mário de Andrade emprega na construção da narrativa de Macunaíma, como se vê no trecho a seguir:

Ia saindo quando topou com o jaguara do gigante, que chamava Xaréu, nome de peixe pra

Revista Crioula - $\mathbf{n}^{\circ} \mathbf{2 6}$ - Relações entre literatura e música na produção de língua portuguesa

$2^{\circ}$ Semestre 2020 
não ficar hidrófobo. O herói teve medo e desembestou numa chispada mãe parque adentro. $\mathrm{O}$ cachorro correu atrás. Correram Correram. Passaram lá rente à Ponta do Calabouço, tomaram rumo de Guajará Mirim e voltaram pra leste. Em Itamaracá Macunaíma passou um pouco folgado e teve tempo de comer uma dúzia de manga-jasmim que nasceu do corpo de Dona Sancha, dizem. Rumaram pra sudoeste e nas alturas de Barbacena o fugitivo avistou uma vaca no alto duma ladeira calçada com pedras pontudas. Lembrou de tomar leite. Subiu esperto pela capistrana pra não cansar porém a vaca era de raça Guzerá muito brava. Escondeu o leitinho pobre. Mas Macunaíma fez uma oração assim:

Valei-me Nossa Senhora,

Santo Antônio de Nazaré,

A vaca mansa dá leite,

A braba dá si quisé!

A vaca achou graça, deu leite e o herói chispou pro sul. (ANDRADE, 2008, p.56).

Nessa passagem do livro, Macunaíma tentava recuperar seu amuleto, a muiraquitã, que estava nas mãos do gigante Venceslau Pietro Pietra. Após fracassar, o herói é caçado pelo cão de Pietro Pietra em uma perseguição digna de figurar nos melhores exemplos de literatura fantástica, pois há ali a total quebra da lógica de tempo e espaço. O protagonista da narrativa, com o cachorro em seu encalço, atravessa vários Estados brasileiros em um curto espaço de tempo, entretanto, o modo como o narrador monta a cena nos dá a impressão de que passar da "Ponta do Calabouço" a "Itamaracá" é somente uma questão de sair de "lá" para ir "ali", naturalizando o aspecto absurdo e artificial da cena. $\mathrm{O}$ que pode parecer mero exercício de fantasia do autor, possui uma função bastante específica na construção da obra, pois como se vê, Macunaíma apresenta desenvoltura e intimidade em todos os cenários perpassados, sendo que os exemplos mais claros estão em sua passagem pelo Nordeste, em Itamaracá, e pelo Sudeste, em Barbacena. No primeiro exemplo observa-se que ele não só reconhece a lenda da manga-jasmim de Itamaracá ${ }^{3}$ como desfruta da iguaria que é tratada como um patrimônio local. No segundo, em sua ida a Minas Gerais, nota-se que o personagem tem conhecimento dos costumes e crendices locais, tanto que faz uso de uma oração popular - inserida em itálico no texto, quebrando o fluxo narrativo - para que a vaca Guzerá possa lhe fornecer leite. Merece atenção também o fato de uma lenda nordestina e uma oração mineira aparecerem em um mesmo trecho, interligando a confusa e extraordinária correria de Macunaíma pelo espaço geográfico brasileiro, o que explicita o caráter de objeto montável da narrativa e enfatiza sua dinâmica da justaposição. A

3 Segundo a lenda, a manga jasmim teria se originado do túmulo de D. Sancha e a mangueira fora semeada por seu pretendente após uma estória de amor mal sucedida. Ver o livro Lendas Brasileiras, de Luís da Câmara Cascudo para mais detalhes. 
exemplo do que se viu em "Perisséia", essa montagem que conecta eventos e imagens diferentes de maneira aparentemente aleatória faz com que Macunaíma se apresente como um ser que integra em sua essência os vários matizes da nacionalidade brasileira, transitando com facilidade pelas lendas da formação cultural do povo nordestino e também pelas tradições mineiras. Cavalcanti Proença em seu estudo sobre o livro, nomeou esse procedimento de "indeterminação temporal", mostrando como substitui-se ali o conceito de vir a ser pelo de coexistência. (PROENÇA, 1987). Assim como se dá com o eu-poético da canção de Tom Zé, a nota predominante aqui é a da multiplicidade, formalizando a ideia de um sujeito que não se limita a um único "eu”. Em "Situação de Macunaíma", Alfredo Bosi estabelece uma linha de interpretação muito feliz para essa questão:

A origem étnica de cada fio cultural de base importa menos do que o tecido resultante; este, sim, assume com o passar do tempo um matiz próprio que se reconhece, afinal, como brasileiro. O herói é herói de nossa gente: fórmula que substituiu, nos manuscritos de Mário de Andrade, a outra, menos feliz, herói de nossa raça.

No entanto, não há em Macunaíma a contemplação serena de uma síntese. Ao contrário, o autor insiste no modo de ser incoerente e desencontrado desse "caráter" que, de tão plural, resulta em ser "nenhum". (BOSI, 2010, p. 200-201).

A técnica utilizada por ambos os artistas se assemelha à prática da bricolageconforme definida por Gilda de Mello e Souza em seu estudo sobre Macunaíma: uma "elaboração criadora complexa" que, incialmente, desarticula os elementos da montagem, "rompendo sua inteligibilidade inicial, para em seguida, insuflar sentido diverso" ao todo resultante do processo. (SOUZA, 2003, p.10). Nas duas obras, o emprego dessa técnica está dialeticamente integrado à mensagem do conteúdo, pois em ambos os casos temos uma estrutura formada por justaposições que visa apresentar o todo como uma complexa junção de elementos variados. Dizendo de outro modo, a composição do músico baiano desarticula o continuum histórico e factual para montar um eu-poético multifacetado, mas que se mostra unificado em sua identidade de sujeito marginalizado. Já a narrativa modernista rompe com a concepção linear de tempo e espaço para apresentar ao leitor um ser que, contraditoriamente, só pode existir enquanto plural. Tanto um exemplo quanto o outro colocam-se como amostras de uma poética macunaímica que visam dramatizar a condição brasileira que consiste em uma dialética rarefeita entre o não ser e o ser outro, conforme afirma Paulo Emílio Salles Gomes(GOMES, 1996).

A semelhança entre os dois métodos de composição, fundamentados pela tensão entre elementos díspares, torna-se ainda mais interessante se considerarmos que um dos pilares de construção de Macunaímase encontra na teoria musical, mais especificamente em dois princípios de composição de canções muito difundidos na história da música ocidental: a suíte e a variação. Isso nos permite 
entender que o literato se utilizou da forma musical ${ }^{4}$ - de modo geral -e o músico se utilizou da formado livro. Seguindo nessa direção, vejamos o raciocínio de Gilda de Mello e Souza:

\begin{abstract}
Macunaíma é composto neste momento de grande impregnação teórica, pesquisa sobre a criação popular e busca de uma solução brasileira para a música. É minha convicção que, ao elaborar seu livro, Mário de Andrade não utilizou processos literários correntes, mas transpôs duas formas básicas da música ocidental, comuns tanto à música erudita quanto à criação popular: a que se baseia no princípio rapsódico da suíte - cujo exemplo popular mais perfeito podia ser encontrado no bailado nordestino do Bumba-meu-Boi-e a que se baseia no princípio da variação, presente no improviso do cantador nordestino, onde assume forma muito peculiar. (SOUZA, p. 12).
\end{abstract}

Em linhas gerais, tanto o princípio da suíte quanto o da variação fornecem ao todo das obras um aspecto híbrido, comparável a uma "verdadeira colcha de retalhos" ou a uma "verdadeira revista de números vários". (SOUZA, p. 14). Logo, guardadas as devidas proporções, são regras básicas de composição que se fundamentam na realocação de elementos retirados de seu contexto inicial em uma estrutura nova, ocasionando assim uma nova fisionomia para o todo doobjeto artístico. Conforme observamos, é essa a lógica que baseia os movimentos de construção analisados na canção e no formato narrativo do livro.

\title{
A Subversão na Forma e na Cultura
}

A partir do que foi apresentado na seção anterior do estudo foi possível verificar que ambas as produções artísticas analisadas são orientadas pela ânsia de montar, sobrepor e multiplicar sentidos, o que acabou sintetizado pelos princípios da suíte e da variação. A adoção desses pressupostos conduz diretamente ao caminho da subversão, dispositivoincontornável para o espírito modernista de Mário de Andrade, assim como para a verve tropicalista de Tom Zé.

Um importante ponto de convergência para essa intenção subversora reside no aspecto épico presente na construção das duas obras. Começando por "Perisséia", já foi destacada aqui a relação existente entre o título e a Odisseia de Homero, mas no caso da canção, Ulisses é substituído por Peri. Além disso, a narrativa presente na canção trata de uma viagem em um navio sem destino cujo navegante tem a impressão de ter se perdido no tempo, remetendo diretamente à saga do herói de Homero em sua tentativa de retornar a Ítaca, sua terra natal. Contudo, como sabemos, Ulisses desafia deuses, ciclopes e todas as peripécias imagináveis em sua viagem, enquanto o a odisseia de Peri reside no enfrentamento das mazelas sociais que o Brasil, alegorizado por Peri e pelo "navio 4 Obviamente, por motivos cronológicos, não está sendo dito que Mário de Andrade se adaptou de alguma forma da canção de Tom Zé, que foi produzida quando Mário já nem era vivo. Refere-se aqui à forma musical de modo geral, às nuances e técnicas composicionais da teoria da música. 
sem destino", possui. Sem querer de modo algum relativizar a gravidade de nossas mazelas, o fato é que Ulisses confronta adversários provenientes de uma esfera sobre-humana, adensando o caráter de grandiosidade e de exceção que há em sua saga. Já na "Perisséia" o herói precisa se digladiar com problemas ocasionados pela incompetência e vulgaridade próprias da esfera humana. Outro aspecto que demonstra essa subversão das referências épicas na canção está no fato do eu-poético desejar apenas "atrasar" o relógio da História para voltar à chegada dos colonizadores portugueses no Brasil para poder rezar pelo seu futuro, instaurando um sentimento ambíguo na composição, situado entre o irônico e o trágico. Ulisses, como se sabe, mesmo contando com favores divinos - Atenas, por exemplo - sempre encara as adversidades de modo altivo, utilizando-se de sua engenhosidade ardilosa e de sua força.

Em Macunaíma essa subversão do épico é um elemento constante na narrativa e já se deixa ver no conflito existente entre a designação de "herói" que Macunaíma recebe e a sua postura carregada de ações pouco glorificáveis: ele mente, chora para ser tratado com piedade, faz pirraça, age em interesse próprio, entre outros exemplos. Mas uma das passagens em que essa tendência fica mais clara é quando Macunaíma, perdido em meio à caatinga brasileira, se depara com a cotia e conta a ela a traquinagem que aprontou com o Currupira. A cotia, contrariada diante do comportamento do moleque resolve banhá-lo com um "bestunto" para que ele cresça e abandone sua meninice:

Então pegou a gamela cheia de caldo envenenado de aipim e jogou a lavagem no piá. Macunaíma fastousarapantado mas só conseguiu livrar a cabeça, todo o resto do corpo se molhou. O herói deu um espirro e botou corpo. Foi desempenando crescendo fortificando e ficou do tamanho dum homem taludo. Porém a cabeça não molhada ficou pra sempre rombuda e com carinha enjoativa de piá. (ANDRADE, p. 20).

A cena é como se fosse o rito de passagem pelo qual Macunaíma deixa de ser "piá" e se torna agora "homem taludo", um herói de verdade. No entanto, como se vê, não sai tudo dentro do planejado e o "bestunto" utilizado pela cotia não atinge todo o corpo do personagem, cuja cabeça continua a ser seu ponto fraco, uma vez que mantem a sua forma infantil. $\mathrm{O}$ ocorrido remete diretamente à imersão de Aquiles nas águas dorio Estige (ou Styx), mas apresenta a versão subvertida ${ }^{5}$ do episódio grego, pois no caso de Aquiles o banho se dá no rio mitológico da invulnerabilidade, cujas promessas nem mesmo os deuses podem quebrar e é executado por Tétis, mãe do futuro guerreiro e ninfa. Em contrapartida, o de Macunaíma ocorre por meio de "bestunto" de aipim envenenado saído da gamela de uma cotia. Aquiles, por um lance de descuido de Tétis, não tem seu calcanhar banhado e aquele passa a ser seu ponto fraco e motivo de sua morte em batalha. Já Macunaíma, "sarapantado", se 5 Gilda de Mello e Souza se utiliza do termo "carnavalização" para se referir ao exemplo. (SOUZA, p. 39). Entretanto, entendo que não seria necessário enveredar-se por esse caminho pois o foco aqui é a analogia do procedimento empregado na canção e na narrativa e não o procedimento em si. 
afasta e assim a lavagem de aipim não banha sua cabeça, fazendo com que apresente uma aparência deformada onde se misturam corpo de homem desenvolvido e cabeça de criança, simbolizando seu desequilíbrio entre um físico capaz de feitos heroicos e a cabeça limitada à imaturidade infantil.

Outro modo de observar essa lógica da subversão nas duas criações artísticas é por meio da relação entre o erudito e o popular. Em "Perisséia" esse traço já aparece na decisão de mesclar referências literárias estrangeiras e nacionais - Odisseia e O Guarani - a fatos do cotidiano contemporâneo à época, como o caso do índio Galdino, utilizando-se de uma linguagem de cunho oral em alguns trechos, como: "Inheminheminhem" e "Iê, Peri”. Porém, é na sonoridade e na estrutura da composição que essa quebra da divisão entre um estilo mais elevado e outro mais popular ${ }^{6}$ se mostra mais contundente. Um exemplo disso se encontra no início da canção, onde é construída uma estrutura rítmica e melódica típica das composições eruditas. Os intervalos e o andamento da execução soam como aquilo que tradicionalmente se denomina como música de orquestra. Entretanto, apesar dessa roupagem, o trecho é construído com solos de cavaco e bandolim, instrumentos altamente populares, o que acaba por desconstruir a separação dos estilos. Um pouco mais à frente no desenvolvimento da cançãoaparece o uso do coro, com contornos sonoros que lembram o canto gregoriano, mas o que se vê nos versos é a referência à capoeira, pelo uso do termo "camará" e o uso de uma construção linguística aproximável à indígena: "Iêperiiêperiiê camará". Esse procedimento, denominado pelo próprio Tom Zé como "Estética do Plágio" está em franca associação com os ideais da estética modernista, podendo ser classificada como uma prática antropofágica. Guilherme de Araújo Freire, em um ensaio sobre o álbum Jogos de Armar, no qual "Perisséia" é uma das faixas, nos descreve o procedimento com precisão:

"Estética do plágio" e o neologismo "plagicombinações" podem serentendidos como uma justaposição de citações da "alta" cultura europeia com músicapopular brasileira. Entendese aqui "alta" cultura europeia pelas obras de compositoresde música erudita, e também de escritores da literatura clássica europeia. Desse modo,em cada faixa do disco, Tom Zé promove um "arrastão estético", ou seja, Tom Zéapropria-se de uma ideia musical, literária ou poética oriunda de uma cultura paratransformar esse material em uma nova ideia poéticomusical, gerando novossignificados, transpostos para outro âmbito cultural e distintos dos sentidos que a ideiaoriginal apresentava. (FREIRE, 2013, p. 34)

No livro de Mário de Andrade, as fronteiras entre a alta cultura e o registro popular também se encontram subvertidas, assim como se pode ver na famosa passagem em que Macunaíma frequenta

6 Os termos são retirados das análises de Erich Auerbach, tanto de sua obra Mimesis, quanto de Ensaios de Literatura Ocidental. Para Auerbach, a combinação entre um estilo baixo e outro alto ocasiona um outro tipo de beleza estética na arte ocidental, diferente daquele ideal preconizado pela rígida separação dos estilos. Em sua análise de As flores do Mal, de Charles Baudelaire, o estudioso chega a associar essa mescla de estilos à irrupção do trágico sublime na literatura. (AUERBACH, 2007). 
um terreiro de macumba:

E pra acabar todos fizeram a festa juntos comendo bom presunto e dançando um samba de arromba em que todas essas gentes se alegraram com muitas pândegas liberdosas. Então tudo acabou se fazendo a vida real. E os macumbeiros, Macunaíma, Jaime Ovalle, Dodô, Manu Bandeira, BlaiseCendrars, Ascenso Ferreira, Raul Bopp, Antônio Bento, todos esses macumbeiros saíram na madrugada. (ANDRADE, p. 69).

Após dez páginas nas quais alguns ritos da religião assumem o foco dos acontecimentos, o narrador encerra o capítulo com o trecho acima, dedicado ao encerramento das atividades no terreiro onde Macunaíma foi pedir um castigo para o gigante Pietro Pietra. A força do elemento popular nessa passagem da obra é explícita, visto que a macumba ocorre na região do Mangue no Rio de Janeiro, na casa de tia Ciata, "uma negra velha com um século no sofrimento" e Macunaíma chega na "biboca levando debaixo do braço o garrafão de pinga obrigatório", onde se avistava representantes variados em um microcosmo tipicamente brasileiro: "gente direita, gente pobre, advogados garçons pedreiros meias-colheres deputados gatunos, todas essas gentes". (ANDRADE, p. 61). É digna de nota também a linguagem utilizada no capítulo - que na verdade, é só mais uma amostra da técnica empregada no livro todo - e que aprofunda ainda mais a feição prosaica da narrativa. Vê-se termos como "essas gentes", "biboca" e a própria sintaxe é ajustada para ganhar um apelo de oralidade, como ocorre quando o narrador enumera os tipos sociais presentes no terreiro. Mas, de repente, ao fim do trecho transcrito acima, insere-se na narrativa uma menção à caravana modernista que acompanhava BlaiseCendrarse visava apresentar ao europeu - e também aos próprios escritores nacionais, restritos a seus ambientes de classe média alta - as entranhas da cultura brasileira. Trata-se de um elemento que, inicialmente, não se liga à natureza do cenário, uma vez que é uma referência intelectual específica, cuja relevância normalmente diz respeito apenas às pessoas que se interessam pelo universo literário brasileiro, contudo, a construção da cena acaba por interligar os dois universos. Essa intençãofica ainda mais claradiante da investida do narrador, que busca escamotear essa separação quando insere Jaime Ovalle e sua trupe no interior da narrativa, ao lado de Macunaíma,e os classifica também como "macumbeiros". A exemplo do que se viu na canção de Tom Zé, opera-se ali um movimento de báscula entre os dois polos que borra as divisões rígidas entre a cultura da elite e a do povo.

\section{Conclusão}

A consonância estética entre a canção e a narrativa não se limita aos exemplos utilizados na análise e poderia render ainda mais reflexões, como exemplo, há a questão da cordialidade e 
da lógica do personalismo, mecanismos igualmente relevantes para o mecanismo de configuração das duas obras. Todavia, espero que o trabalho de interpretação realizado nas linhas escritas acima possa ter deixado claro como se dá a homologia formal entre "Perisséia" e Macunaíma, exercício capaz de nos mostrar que a comparação entre realizações de campos artísticos diversos pode ser um modo produtivo para iluminarmos melhor suas especificidades. Juntamente a isso, é importante ressaltar também a potencialidade histórica e social da forma artística, pois como vimos, seja no uso do procedimento da sobreposição ou na fusão entre elementos de ordens culturais diferentes, a disposição estética da obra sempre pode nos ofertar uma chave de interpretação para a realidade em que vivemos. No caso, tanto Tom Zé quanto Mário de Andrade, nos ensinam que a nossa, a brasileira, é múltipla, complexa e contraditória.

\section{Referências Bibliográficas:}

ADORNO, Theodor W. Filosofia da Nova Música. $3^{\mathrm{a}}$ ed. São Paulo: Perspectiva, 2009.

ADORNO, Theodor W. Teoria Estética. Coimbra: Edições 70, 2011.

ANDRADE, Mario de. Macunaíma: o herói sem nenhum caráter. Rio de Janeiro: Mediafashion, 2008. (Coleção folha grandes escritores brasileiros).

AUERBACH, Erich. Ensaios de Literatura Ocidental: filologia e crítica. São Paulo: Duas cidades, 2007.

BOSI, Alfredo. "Situação de Macunaíma”. In: BOSI, Alfredo. Céu e Inferno: Ensaios de crítica literária e ideologia. 2.ed. São Paulo: Editora 34, 2010. p. 187-207.

CANDIDO, Antonio. O discurso e a Cidade. 4ed. Rio de Janeiro: Ouro Sobre azul, 2010.

CASCUDO, Luís da Câmara. Lendas Brasileiras. São Paulo: Global Editora, 2015.

DUNN, Christopher. Fazendo cócegas nas tradições: o samba disjuntivo de Tom Zé.In: Revista do Instituto de Estudos Brasileiros, Brasil, n. 70, p. 149-165, ago. 2018.

FREIRE, Guilherme Araújo. Tom Zé e o elogio à imperfeição: uma breve análise do disco Com Defeito de Fabricação. In: Revista brasileira dos estudos da canção, Natal, n.3, p.24-37, Jan-Jun, 2013. 
GOMES, Paulo Emilio Sales. Cinema: trajetória no subdesenvolvimento. Rio de Janeiro: Paz e Terra, 1996. (Coleção Leitura).

PROENÇA, Manuel Cavalcanti. Roteiro de Macunaíma. $6^{\text {a }}$ ed. Rio de Janeiro: Civilização Brasileira, 1987.

SOUZA, Gilda de Mello e. O tupi e o alaúde: uma interpretação de Macunaíma. São Paulo: Duas Cidades; Editora 34, 2003. 